\title{
ON TESTS FOR LONG-TERM DEPENDENCE: INDIA'S INTERNATIONAL TOURISM MARKET
}

\author{
Prasert Chaitip ${ }^{1}$, Péter Balogh², Kovács Sándor $^{3}$ \& Chukiat Chaiboonsri ${ }^{4}$
}

\author{
${ }^{1}$ Faculty of Economics, Chiang Mai University, Chiang Mai, Thailand E-mail: webadmin@econ.cmu.ac.th \\ ${ }^{2}$ University of Debrecen, Centre for Agricultural and Applied Economic Sciences, Faculty of Applied Economics \\ and Rural Development, Institute of Economic Analitical Methodology and Applied Informatics, Department of \\ Economic Analysis and Statistics E-mail: baloghp@agr.unideb.hu \\ ${ }^{3}$ Centre for Agricultural and Applied Economic Sciences, Faculty of Applied Economics and Rural Development, \\ Institute of Economic Analitical Methodology and Applied Informatics, Department of Economic Analysis and \\ StatisticsE-mail: kovacss@agr.unideb.hu \\ ${ }^{4}$ Faculty of Economics, Chiang Mai University, Chiang Mai, Thailand E-mail: chukiat1973@yahoo.com
}

\begin{abstract}
There have been growing interest in studying behavior of long memory process in tourism market. In this research examine the behavior of India's international tourism market based on long-memory analysis. The international tourism market of India combined with nine countries: USA, UK, Canada, Germany, France, Japan, Malaysia, Australia and Sri Lanka. Moreover, three statistical tests for longmemory process such as R/S test, Modified R/S test and GPH-test are employed to test in these market. The empirical findings in general provide more support for no long memory process or no long-term dependence in international tourism market of India.
\end{abstract}

Key words: India, Long-memory process, Long-term dependence, International Tourism Market

\section{Introduction}

The international tourism industry in India is of great importance as it has positive impact on India's economy. Fore example, contributing to the nation's gross domestic product is $6 \%-7 \%$ in during period of 2003-2004, India's foreign exchange earnings through tourism is 5,731 million US. Dollar in 2005 and contributing to labor market is $9 \%$ of India's employment in during period of 2003-2004. Tourists to India spent $\$ 372$ on their visa cards in the year of 2005 . This is a $25 \%$ rise from the year 2004 thereby, making India the fastest growing Asia -Pacific market for the International tourist spending. According to the World Travel and Tourism Council, the Indian tourism demand will grow at an annual $8.8 \%$ over the next ten years, fueled by higher incomes and lower air fares. Moreover, In 2005 India earned US \$ 6.9 billion from inbound foreign tourists, which is more than twice the US \$3.1 billion earned during the year 2002 . According to the latest balance of payments figures released by the Reserve Bank Of India, 2005 was the year of fastest growth in foreign inflows from foreign travel, during which inflows went up $36 \%$. The above mentioned information has motivated us to understand the international tourism market behavior more and conduct the present research study.

Time series with long memory process was appeared in many contexts such as in financial economics, macroeconomics series, hydrology, cardiac dynamics, networks traffic, meteorology. Evidence of long memory process was first proposed by Hurst in 1951 when he testing the behavior of water levels in the Nile river. In 1971, Mandelbrot was among the first to consider the possibility of long range dependence or long memory process in asset returns. And in 1998, Wright, J. studied about the detection evidence of long memory in stock returns in many emerging market such as in Korea, Philippines, Greece, Chile and Colombia. Moreover, Caporale and Gil-Ala (2002), studied the S\&P 500 daily returns and they found that the degree of dependence remains relatively constant overtime, with the order of integration of stock returns fluctuating slightly above or below zero. Olan (2002) studied the long memory in stock returns from an international market perspective and also found no evidence for long memory in UK, U.S., Hong Kong, Singapore and Australian stock markets. However, evidence for long memory can be found in the German, Japan's, South Korean and Taiwan stock market. In connection with international tourism the long memory process analysis was begun by GilAlana (2005). He examines forecasting properties of shortterm arrivals at Auckland international airport and finds that the ARFIMA models outperform the non-ARFIMA ones in practically all case. After that Chu (2008) incorporates ARFIMA models into Singapore's tourism forecasting and compares the accuracy of forecasts with those obtained by earlier studies. Recently, Sriboonchitta et. al. (2010) used forecasting method based on both ARFIMA models and 
ARFIMA-FIGARCH to forecast the number of international tourists arrival to Thailand and they also found that the longmemory process behavior in their model to forecast. In many articles authors have not yet tested the long memory process in international tourism market based on R/S Test, Modified R/S Test and GPH Test. For this reason this paper would like to apply tests of Long-memory in international tourism market of India based on data from the period of 1981-2007.

\section{Research Aim and Objective}

This research aims to test the long memory behavior in both the Indian and Thailand's international tourism market between 1981-2007.

\section{Scope of this research}

The scope of this research covers during period of 19812007 and mostly the data was secondary data. The countries were used for testing the long memory behavior are all the countries have impact on the international tourism industry of India such as USA, UK, Canada, Germany, France, Japan, Malaysia, Australia and Sri Lanka (Ministry of Tourism, Govt. of India 2009). The variables used in this research were the numbers of international tourist arrivals to India from the above mentioned countries during 1981-2007.

\section{The research framework of Long Memory Tests}

The concept of the long memory process was developed by Harold Edwin Hurst in 1906. He was a young English civil servant, came to Cairo, Egypt, which was then under British rule. As a hydrological consultant, Hurst's problem was to predict how much the Nile flooded from year to year. He developed a test for long-range dependence (Long Memory Test) and found significant long-term correlations among fluctuations in the Nile's outflows and described these correlations in terms of power laws. This statistic is known as the rescaled range, range over standard deviation or $R / S$ statistic. From 1951 to 1956 , Hurst published a series of papers describing his findings (Hurst 1951). Hurst's rescaled range $(R / S)$ statistic is the range of partial sums of deviations of a time series from its mean, rescaled by its standard deviation. The definition of long memory process can be explained by the so called autocovariance function $\gamma$ ( $\mathrm{k})$, where $\mathrm{k}$ is the lag parameter. The long-memory process can be defined as follows:

$$
\operatorname{Lim}_{\mathrm{k} \rightarrow \infty} \gamma(\mathrm{k}) \sim \mathrm{k}^{-\alpha} \mathrm{L}(\mathrm{k})
$$

where $0<\alpha<1$ and $\mathrm{L}(\mathrm{x})$ is a slowly varying function at infinity. Because $\mathrm{L}(\mathrm{x})$ is a slowly function if $\lim \mathrm{x}->\infty$ $\mathrm{L}(\mathrm{tx}) / \mathrm{L}(\mathrm{x})=1$ (see Embrechts et al., 1997). The degree of long memory is given by the exponent $\alpha$; smaller $\alpha$ means longer memory. The long memory is also discussed in terms of the Hurst exponent $H$, which is simply related to $\alpha$. For a long memory process $H=1-\alpha / 2$ or $\alpha=2-2 H$. The short memory processes have $H=1 / 2$, and the autocorrelation function decays faster than $\mathrm{k}^{-1}$. A positively correlated longmemory process is characterized by the Hurst exponent in the interval $(0.5,1)$.

\subsection{Test for Long Memory: R/S Test}

The Long Memory test based on R/S test has been developed by Hurst (1960) and Mandelbrot and Wallis (1969) method allows computing parameter $H$, which measures the intensity of long rang dependence in time series. The time series of length $\mathrm{T}$ is divided into $n$ sub-series of length $m$. For each sub-series $m=1, \ldots, n$, we have to find the mean $\left(\mathrm{E}_{\mathrm{m}}\right)$ and standard deviation $\left(\mathrm{S}_{\mathrm{m}}\right)$, and subtract the sample mean using the formula below:

$$
\mathrm{Z}_{\mathrm{i}, \mathrm{m}}=\mathrm{X}_{\mathrm{i}, \mathrm{m}}-\mathrm{E}_{\mathrm{m}} \text {, for } \mathrm{i}=1, \ldots \ldots, \mathrm{m} \text {. }
$$

After that we could produce a time serie from the sample means as $\mathrm{W}_{\mathrm{i}, \mathrm{m}}=\sum_{j=1}^{i} Z_{j, m}$ where $\mathrm{i}=1, . ., \mathrm{m}$ and the range is calculated as the below given formula:

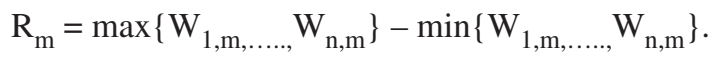

The rescaled range is calculated by $\frac{R_{m}}{S_{m}}$ as well as in case of time series $R, S$ and $H$ can be defined according to the formulas below:

- where $\mathrm{R}$ is the distance covered by the variable, $k$ is a constant and $\mathrm{T}$ is the length of the time.

$$
R=k \times T^{0.5}
$$

- where $\mathrm{R} / \mathrm{S}$ is the rescaled range, $\mathrm{m}$ is the number of observations, $\mathrm{k}$ is a constant and $H$ is the Hurst exponent, can be applied to a bigger class of time series.

$$
\frac{R}{S}=k \times m^{H}
$$

- The Hurst exponent can be calculated as: $\log (R / S) \mathrm{m}=\log \mathrm{k}+\mathrm{H} \log \mathrm{m}$

and can be interpreted as:

- If $H$ value $=0.5$ then time series follow a random walk and are independent.

- If $H$ value $=(0,0.5)$ then time series are antipersistent, process covers only a small distance than in the random walk case.

- If $H$ value $=(0.5,1)$ then time series are persistent series, process covers bigger distance than a random walk (long memory process). 


\subsection{Test for Long Memory: Modified R/S Test}

The modified R/S test is developed from the classical R/S test which was proposed by Hurst (1951) while studying hydrological time series of the River Nile. For a return series $\left\{\mathrm{x}_{1}, \mathrm{x}_{2}, \ldots \ldots \ldots, \mathrm{x}_{\mathrm{T}}\right)$, Lo (1991) refined the classical test by defining (see equation (1))

$$
\mathrm{Q}_{\mathrm{T}}=\quad \hat{R^{\prime}} \hat{\sigma}_{T}^{\wedge}(q)
$$

where

$$
\begin{gathered}
\hat{\mathrm{R}}=\underset{0 \leq i \leq \mathrm{T}}{\operatorname{MAX}} \sum_{\mathrm{t}=1}^{\mathrm{i}}\left(\mathrm{X}_{\mathrm{i}}-\overline{\mathrm{X}}\right)-\underset{0 \leq i \leq \mathrm{T}}{\operatorname{MIN}} \sum_{\mathrm{t}=1}^{\mathrm{i}}\left(\mathrm{X}_{\mathrm{i}}-\overline{\mathrm{X}}\right) \\
\sigma_{T}^{\wedge 2}(q)=\sigma^{\wedge 2}+2 \sum_{j=1}^{q} w_{j}(q) \hat{\gamma}_{j}, \\
w_{j}(q)=1-|j / q|,
\end{gathered}
$$

and define that:

$$
\begin{aligned}
& \sigma^{\wedge 2}=\text { the usual sample variance of data } \\
& \bar{X}=\text { the mean of data } \\
& \gamma_{j}=\text { lag }-\mathrm{j} \text { autocovariance for the data and the } \\
& \text { truncation lag } \mathrm{q} \text { is determined by equation } 2
\end{aligned}
$$

$$
\mathrm{q}=\operatorname{int} \quad\left[((3 T) / 2)^{1 / 3}\left((2 \rho) / 1-\rho^{\wedge 2}\right)^{2 / 3}\right] \text {. }
$$

Where $\rho^{\wedge}$ is the first the first-order sample autocorrelation coefficient and int [ ] is the integer function. Under the null hypothesis of no long memory or no long rang dependence, Lo (1991) presented that the limiting distribution of the $\mathrm{Q}_{\mathrm{T}}$ statistics in equation 1 is given by the distribution function of the difference between maximum and minimum of Brownian bridge on a unit interval. Therefore, it can easily obtain the p-value of the test.

\subsection{Test for Long Memory: GPH Test}

The GPH Test for Long Memory process was developed by Geweke. and Porter-Hudak (1983) and they proposed to estimate of the OLS estimator of $d$ from the regression: (Equation 3)

$$
\ln [I(\xi)]=a-\hat{d} \ln \left[\sin ^{2}\left(\frac{\xi_{\lambda}}{2}\right)\right]+e_{\lambda},
$$

where

$$
/(\xi)=\quad \frac{1}{2 \pi T}\left|\sum_{t=1}^{T} e^{i t \xi}\left(x_{t}-\bar{x}\right)\right|^{2}
$$

And the equation 4 is the Periodogram (estimator of spectral density) of $x$ at a frequency $(\xi)$

as well as the bandwidth $\mathrm{v}$ is chosen such that for

$$
T \rightarrow \infty, v \rightarrow \infty \quad \text { but } \frac{v}{T} \rightarrow 0
$$

Geweke and Porter-Hudak consider that the power of T has to be within $(0.5,0.6)$ and for the null hypotheses of no long memory process, the slope of regression $d$ equals zero and the usual t-statistics can be employed to perform the test.

\subsection{Data Description}

Table 1 presents the number of international tourists arrived to India during 2003-2007. In 2003 the number of international tourists arrived to India was 2.7 million and in 2004 this number increased to 3.4 million comparing with last year. Moreover, in 2005 the number of international tourist arrivals to India also have increased continuously. In this year the number of tourists came to India was 3.9 million. Table 1 clearly suggests that the number of international tourist arrivals to India has increased from year to year. Table 2 presents the foreign exchange earnings from international tourist arrivals to India during the period of 2005-2007. In 2005 Indian economy received foreign exchange earnings from international tourism industry was 1.5 thousand million US Dollar. Moreover, in 2006 the India's economy received 1.7 thousand million US Dollar as foreign exchange earnings from this industry. Finally. the foreign exchange earnings from this industry have increased 2.06 thousand million US Dollar in 2007 (Table 2). Based on these data we could clearly confirm that the international tourism industry of India will definitely become the potential industry for the future.

Table 1. Number of the international tourist arrivals to India between 2003 and 2007

\begin{tabular}{|l|c|c|c|c|c|}
\hline Denomination & $\mathbf{2 0 0 3}$ & $\mathbf{2 0 0 4}$ & $\mathbf{2 0 0 5}$ & $\mathbf{2 0 0 6}$ & $\mathbf{2 0 0 7}$ \\
\hline January & 274,215 & 337,345 & 385,977 & 459,489 & 532,088 \\
\hline February & 262,692 & 331,697 & 369,844 & 439,090 & 498,806 \\
\hline March & 218,473 & 293,185 & 352,094 & 391,009 & 444,186 \\
\hline April & 160,941 & 223,884 & 248,416 & 309,208 & 333,945 \\
\hline May & 141,508 & 185,502 & 225,394 & 255,008 & 267,758 \\
\hline June & 176,324 & 223,122 & 246,970 & 278,370 & 310,104 \\
\hline July & 225,359 & 272,456 & 307,870 & 337,332 & 377,474 \\
\hline August & 204,940 & 253,301 & 273,856 & 304,387 & 360,089 \\
\hline September & 191,339 & 226,773 & 257,184 & 297,891 & 325,893 \\
\hline October & 260,569 & 307,447 & 347,757 & 391,399 & 440,715 \\
\hline November & 290,583 & 385,238 & 423,837 & 442,413 & 510,987 \\
\hline December & 319,271 & 417,527 & 479,411 & 541,571 & 575,148 \\
\hline Total & $2,726,214$ & $3,457,477$ & $3,918,610$ & $4,447,167$ & $4,977,193$ \\
\hline
\end{tabular}

Sources of data: Ministry of Tourism, Govt. of India, 2010

Table 2. Foreign exchange earnings from international tourist arrivals to India between 2005 and 2007

Unit: US \$ Million

\begin{tabular}{|l|c|c|c|}
\hline Months & $\mathbf{2 0 0 5}$ & $\mathbf{2 0 0 6}$ & $\mathbf{2 0 0 7}$ \\
\hline January & 532.19 & 632.43 & 744.58 \\
\hline February & 536.07 & 594.67 & 680.41 \\
\hline March & 505.74 & 547.17 & 636.05 \\
\hline Total & $1,574.00$ & $1,774.24$ & $2,061.04$ \\
\hline
\end{tabular}

Sources of data: Ministry of Tourism, Govt. of India, 2010 


\section{The results of various tests for Long Memory Process or Long-term dependence process}

Table 3 shows the results of various tests for long memory process regarding R/S Test, Modified R/S Test and GPH Test of India's international tourism market between 1981and 2007. Several countries are international tourism markets of India. For instance, USA, UK, Canada, Germany, France, Japan, Malaysia, Australia and Sri Lanka (Ministry of Tourism, Govt. of India, 2009).

Table 3. Results of Various Tests for Long Memory based on R/S Test, Modified R/S Test and GPH Test

\begin{tabular}{|l|c|c|c|}
\hline Country & R/S Test & Modified R/S Test & GPH Test \\
\hline USA & $2.010^{*}$ & 1.2659 & 1.4874 \\
\hline UK & $2.0402 *$ & 1.2838 & 1.3577 \\
\hline Canada & $2.0219 *$ & 1.2784 & 1.5063 \\
\hline Germany & 1.1541 & 1.1392 & 0.6048 \\
\hline France & 1.7879 & 1.1729 & 1.0971 \\
\hline Japan & $2.1268 * *$ & 1.3809 & 1.2209 \\
\hline Malaysia & $2.0735^{*}$ & 1.294 & 1.6528 \\
\hline Australia & 2.0369 & 1.323 & 1.2145 \\
\hline Sri Lanka & $2.1529 * *$ & 1.4117 & 1.3119 \\
\hline
\end{tabular}

Sources of data: computed

Null Hypothesis: no long-term dependence or no long memory process.

For GPH test, Null Hypothesis: $\mathbf{d}=\mathbf{0}$.

$*$ : significant at $5 \%$ level, ** : significant at $1 \%$ level

The test results are summarised in Table 3. For each test, the test statistics and the corresponding significances are given. If the value of R/S Test, Modified R/S Test and GPH Test are significant at $1 \%$ level or at $5 \%$ level then there is a long-term dependence or long memory process in the time series data. Otherwise no long-term dependence or no long memory process exists in the time series data. The empirical results of long memory process analysis based on both Modified R/S Test and GPH Test proved that all the international tourism markets of India have not a long-term dependence in themselves. Otherwise, based on R/S Test we can claim that most of the international tourism markets have a long memory process in themselves On the other hand we could not decide on direction of the arrival changes. However, the Modified R/S Test and GPH test have already confirmed that the international tourism markets of India have not a long-term dependence process in themselves, only the R/S Test has already confirmed that the international tourism markets of India have a long-term dependence process in themselves except Germany, France and Australia.

\section{The conclusions of research and policy recommendations}

This research provides various tests for long memory process (R/S Test, Modified R/S Test and GPH Test) to study the international tourism markets of India during the period 1981-2007. The empirical results of this research concluded that most international tourism markets of India are not long memory processes. The Long Memory or Long range dependence means that the information from "today" is not immediately absorbed by the price in the market and investors react with delay to any such information (Bardos, 2008).

This fact implies that the international tourism markets of India are effected by any information immediately or quickly. This result was different from the results of previous empirical studies of long memory process in international tourism market (Gil-Alana, 2005; Chukiat and Prasert, 2009 ) .

If these results can be generalized for future years, then it suggests that both the Indian government sector and the private tourism industry sector of India need to protect the bad information of this industry and information can not go outside from India to other country. Otherwise, experts should develop tourism market of India more and further develop tourism product in India too. In terms of the tourism market development, experts need to launch an active marketing campaign, promoting India's exclusive culture and natural beauty through every channel especially the internet, and keep high quality of accommodation, restaurants, and services in tourism market of India as well. In terms of tourism product development, experts need to keep on improving both the quality and management of tourist products in India. Fore example, to develop tourist destinations in India, provide educational of tourism to people in the tourism industry of India and decrease the negative image of tourist destinations in India. Moreover, keeping tourist destinations clean, keeping tourist destinations beautiful, keeping tourist destinations safety and to protect the environment of tourist destinations. The private tourism sector and the India government tourism sector should maintain good management of tourist destinations in India. Such as maintaining the amenities of the tourism products, keeping good accessibility to the tourism products, keeping a good image of tourism products, keeping the right price of tourism products and keeping the competitiveness of tourism products (Chaitip and Chaiboonsri, 2009).

\section{References}

Baillie, R.T. (1996): Long memory processes and fractional integration in econometrics. Journal of Econometrics, Volume 73, Issue 1, July 1996, Pages 5-59.

Bardos, S. (2008): "Academy of Economic Studies - Bucharest Doctoral School of Finance and Banking DOFIN", Bucharest, July 2008

Campbell, J.Y., Lo, A.W., \& Mackinlay, A.C. (1997): The Econometrics of Financial Markets. Princeton University Press.

Caporale \& Gil-Allana, (2002): "Fractional integration and mean reversion in stock prices", Quarterly Review of Economics and Finance 42 (2002), pp. 599-609. 
Chaitip, P. \& Chaiboonsri, C. (2009): "Down Trend Forecasting Method With ARFIMA: International Tourist Arrivals to Thailand", Annals of the University of Petrasani, Economics, 9(1), 2009, 143-150.

Deboeck, G.J. (ed.) (1994): Trading on the Edge: Neural, Genetic, and Fuzzy Systems for Chaotic Financial Markets, John Wiley \&amp; Sons, Inc.

Embrechts, P., Klüppelberg, C. \& Mikosch, T. (1997): "Modelling Extremal Events for Insurance and Finance", Springer, Berlin.

Geweke, J. \& Porter-Hudak, S. (1983): "The estimation and application of long memory time series models", Journal of Time Series Analysis, Vol. 4 pp. 221-238.

Gil-Alana, L.A. (2005): "Modelling international monthly arrivals using seasonal univariate long-memory processes", Tourism Management, Volume 26, Issue 6, December 2005, Pages 867-878

Gil-Alana, (2005): "Modeling international monthly arrivals using seasonal univariate long-memory processes", Tourism Management 26 (2005), pp. 867-878

Giraitis, L., Kokoszka P. And Leipus, R. (2001): Testing for Long Memory in the Presence of a General Trend, Journal of Applied Probability, Vol. 38, No. 4. (Dec., 2001), pp. 1033-1054.

Henry, (2002): "Long memory in stock returns. Some international evidence", Applied Financial Economics 12 (2002), pp. 725-729.

Hurst, H.E. (1951): Long-term storage capacity of reservoirs. Transactions of the American Society of Civil Engineers, Volume 116, Pages 770-799.

Kirman, A. \& Teyssiere, G. (2002): Bubbles and long range dependence in asset prices volatilities. forthcoming in Hommes $C$., R. Ramer and C. Withagen (eds.).

Lebaron, B., (2001): Empirical regularities from interacting long- and short-memory investors in an agent-based stock market, IEEE Transactions on Evolutionary Computation, Volume 5, Issue 5, October.

Lo, A.W. (1991): Long-term memory in stock market prices. Econometrica 59, pp. 1279-1313.
Mandelbrot, B.B. \& Wallis, J.R., (1969): Robustness of the rescaled range $\mathrm{R} / \mathrm{S}$ in the measurement of noncyclic long-run statistical dependence. Water Resour. Res. 5, pp. 967-988.

Mandelbrot, B.B. \& Wallis, J.R., (1969): Some long-run properties of geophysical records. Water Resour. Res. 5, pp. 321-340.

Mandelbrot, B.B., (1997): Fractals and Scaling in Finance, Springer New York.

Mandelbrot, B.B., \& Wallis, J.M. (1969): "Robustness of the rescaled range $\mathrm{R} / \mathrm{S}$ in the measurement of noncyclic long run statistical dependence", Water Resources Research, 5:967-988.

Ministry of Tourism, Government of India. (2010): Retrieved January 25, 2010 from http://tourism.gov.in/

Montanari, A., (2003): Long-range dependence in hydrology. Theory and Applications of Long-Range Dependence, edited by

Peters, E.E., (1996): Chaos and Order in the Capital Markets: A New View of Cycles, Prices, and Market Volatility, New York: John Wiley \&amp; Sons, Inc.

Robinson, P.M. (ed.) (2002): Time Series with Long Memory, Oxford University Press.

Simonsen, I., Hansen, A. \& Nes, O.M. (1998): Determination of the Hurst exponent by use of wavelet transforms, Physical Review E, Volume 58, Number 3, Pages 2779-2787, September 1998.

Sriboonchitta, S., Jittaporn, Chaitip, P. \& Chaiboonsri C. (2010): "International Tourist Arrivals in Thailand Forecasting with ARFIMAFIGARCH Approach", The Third Conference of Thailand Econometric Society, Chiang Mai, Thailand, 7-8 January 2010.

Taqqu, M.S., Teverovsky, V. \& Willinger, W. (1995): Estimators for long-range dependence: An empirical study, Fractals, Vol. 3, No. 4 (1995) 785-798.

Wright, J., (1998): "Testing for a Structural Break at Unknown Date with. Long-Memory Disturbances," Journal of Time Series Analysis, 19, 369-379. 
